\title{
EFFECT OF TASK ORIENTED TRAINING ON BALANCE IN CHILDREN WITH HEMIPARETIC CEREBRAL PALSY
}

Hamada T. Mohamed ${ }^{1}$; Gehan M. Abd El-Maksoud ${ }^{2}$; Heba H. Abd El-Wahaab ${ }^{3}$ and Amr A. Azam ${ }^{4}$

1 Physical Therapist, The National Institute Of Neuromotor System, Egypt.

2 Professor of Physical Therapy for Pediatrics, Faculty of Physical Therapy, Cairo University, Egypt.

3 Lecturer of Physical Therapy for Pediatrics, Faculty of Physical Therapy, Cairo University, Egypt.

4 Consultant of Orthopedic Surgery, The National Institute of Neuromotor System, Egypt.

Key Words: Balance, Cerebral palsy, Hemiplegia, Pediatric balance scale and Task Oriented Training.

\section{ABSTRACT}

Background: Task oriented training is widely recognized as an effective method to enhance balance. Purpose: The aim of this study was to investigate the effect of task oriented training on balance in children with hemiplegic cerebral palsy. Subjects and Methods: Fourteen children with hemiplegic cerebral palsy, aged from 6 to 9 years of both sexes were participated in this study. They were selected from the outpatient clinic of the National Institute of Neuromotor System. They were assigned into one group, (study group). They received task oriented training program. The treatment program was conducted for one hour, three times per week for three successive months for this group. Pre- and post-treatment assessments of balance were performed by Pediatric Balance Scale (PBS). Results: This group showed significant improvement in balance $(\mathrm{p}<0.000)$ after treatment protocols. Conclusions: Task oriented training may be used as an effective method in the rehabilitation program for children with hemiplegic cerebral palsy to improve their balance.

\section{INTRODUCTION}

Cerebral palsy (CP) describes a group of permanent disorders of the development of movement and posture, causing activity limitations that are attributed to non-progressive disturbances in the developing fetal or infant brain ( Rosenbaum et al., 2006). It is also defined as neurodevelopmental condition beginning in early childhood and persisting throughout one's life span. The average incidence is approximately 2-2.5 per 1000 live births (Odding et al., 2006). 
Hemiplegic cerebral palsy (HCP) is a unilateral paresis, with upper limbs more severely affected than the lower limbs. Hemiplegia accounts for $20 \%$ to $30 \%$ of all cases of CP, and is caused predominantly by unilateral damage of the developing brain which leads to unilateral, asymmetric muscle tone abnormalities, and deformities. As a consequence, patients with HCP show unilateral, irregular movements and limitations in range of motion (Feltham et al., 2010).

In order to orient the body, while keeping balance, visual, vestibular and somatosensory modalities are also involved. Every directed activity implies that the body was previously oriented, although, any part of the body surface can influence the control and perception of body orientation (Jauregui, 2013).

Children with spastic hemiplegia experience decreased balance ability and abnormal gait because of decreased weight-bearing in the paretic leg. Diminished motor ability in the paretic leg causes weakening of the quadriceps, ankle plantar flexors, and ankle dorsiflexors (Ki et al., 2015).

Task-oriented training is defined as the repetitive training of significant, functional activities or element of such activities, to acquire well-organized and effective motor skill. It used as a rehabilitation strategy to improve motor skill and as a rehabilitation program for improvement of muscle strength, balance and function (Leroux et al., 2006). It should include specific tasks to improve function as an effective treatment for functional improvement of patients with disorders of the central nervous system (CNS) (Bayona et al., 2005).

Task oriented training is a form of motor learning that focus on skill acquisition in the context of a particular functional activity. Skill is the ability to achieve the goal with consistency, flexibility and efficiency. Task oriented training for patient with CNS lesion results in motor relearning by enhancing skill in meaningful functional activity with adaptive neuroplastic changes in the cerebral cortex, brain stem, cerebellum and spinal cord. There is a growing interest in the phenomena of neural plasticity following CNS injury and its critical link to taskoriented training (Stein, 2009). Also, Ching et al. (2013) concluded that, task oriented training improves motor performance, motor control strategies, sensory recovery, balance and daily function more than the traditional treatment. The aim of this study was to investigate the effect of task oriented training on balance in children with hemiparetic CP.

\section{Study Design}

\section{MATERIALS AND METHODS}

This study was a Quasi-experimental study that was conducted from April 2019 up to July 2019. 


\section{Subjects}

A sample of fourteen children with hemiplegic $\mathrm{CP}$ of both sex agreed to participate in the present study with their ages ranged from six to nine years. They were selected from the outpatient clinic of the National Institute of Neuro Motor System. They had a diagnosis of hemiplegic cerebral palsy that was obtained from their medical records and confirmed by radiological examination and neurologist. They had spasticity grade 1 and $1+$ according to Modified Ashwarth Scale. The children were at level I and II on Gross Motor Function Classification System (GMFCS) and able to follow instructions during evaluation and treatment procedures. Participants were excluded from this study if they had any of the following; fractures of upper and lower limbs, visual, auditory, or perceptual deficits, surgical interference for the lower limb, seizures or epilepsy, received botulinum toxin in the lower extremity musculature during the past 6 months.

Approval by the Ethical Committee of the Faculty of Physical Therapy, Cairo University (0121002186), and written consent forms from parents of children, were obtained at the beginning of the study.

\section{Procedures}

\section{A) Evaluative procedure}

Balance was evaluated for all children participated in this study using pediatric balance scale pre and post treatment in order to track progress in a rehabilitation program.

Pediatric Balance Scale (PBS) was developed by Franjoine et al. (2003). The purpose of PBS is to examine functional balance in the context of daily life's activities in the pediatric population. It contains functional measured items, which are sitting to standing, standing unsupported, standing to sitting, sitting unsupported, transfer standing with eyes closed, standing with feet together, standing with one foot in front, standing on one foot, turning $360^{\circ}$, turning to look behind, retrieving object from floor, placing alternate foot on stool and reaching forward with outstretched arm. The score level of each item will be recorded on a five-point liker scale (from 0 to 4 ), depending on the quality of performance. Total score ranged from 0 to 56 . Higher score indicates better functional balance ability (Lei et al., 2017).

Pediatric balance scale was used to assess balance for all children participated in this study. It contains 14-item. Scoring for each item is scored 0 points (lowest function) to 4 points (highest function), with a 
maximum score of 56 points. Calculation of the total score by summation of the score of the 14 items (Franjoine et al., 2010).

B) Treatment procedures

Children in this study group received task-oriented training program for one hour, three sessions per week for three successive months according to the protocol of Citation and Ostwal (2016). The program included the following exercises: -

1) Reaching in different directions for objects located beyond arm's length

2) Sit-to-stand from various chair heights

3) Kicking ball

4) Walking forward, sideway and backward

5) Jumping from different height

6) Standing on one limb

7) Up and down stairs training

8) Stepping forward and backward onto blocks of various heights

9) Stepping sideways onto blocks of various heights

10) Forward step-up onto blocks of various heights

11) Raising and lowering heel while maintaining a standing posture.

12) In addition to the previous program, the children received the following exercises:

a. Stretching exercises for shortened muscles.

b. Strengthening exercises for weak muscles.

c. Balance exercises on balance board

Data Analysis

Data were statistically described in terms of mean \pm standard deviation $( \pm S D)$, or frequencies (number of cases) and percentages. Numerical data were tested for the normal assumption using Kolmogorov Smirnov test and Shapiro Wilk test. Student t- test was used to compare the pre and post treatment results of the study group. $\mathrm{P}$ values less than 0.05 was considered statistically significant. All statistical calculations were done using computer program IBM SPSS (Statistical Package for the Social Science; IBM Corp, Armonk, NY, USA) release 22 for Microsoft Windows.

\section{RESULTS}

Seventeen children with hemiplegic CP children were screened for participation in the current study. Two children were excluded because they failed to fulfill the inclusion criteria, and one child's parents refused to participate in the study. The remaining fourteen children were 
allocated into one group. This study group received a designed taskoriented training program.

\section{Demographic and clinical data of the subjects}

Table (1) reveals the mean values of age and the distribution of gender, affected side, grade of spasticity and level of GMFCS of the study sample. The mean values of age were $6.96 \pm 0.987$ years old of study sample. The gender distribution revealed the number (percentage) of boys and girls in this study sample which were and $8(57.1 \%), 6$ (42.9\%) respectively. The affected side distribution the number (percentage) of right and left side affection in the study sample which were $10(71.4 \%)$ and $4(28.6 \%)$, respectively. The grade of spasticity distribution revealed the number (percentage) of grade 1 and $1+$ in this study which were 2(14.3\%), 12 (85.7\%) respectively. Gross Motor Function Classification System distribution revealed the level 1 and 2 in this study group which were $5(35.7 \%)$ and $9(64.3 \%)$, respectively.

Table (1): Demographic and clinical data of subjects

\begin{tabular}{|l|l|}
\hline Item & Number (percentage) \\
\hline Gender & \\
Girls & $6(42.9 \%)$ \\
Boys & $8(51.15 \%)$ \\
\hline Affected side & $10(71.4 \%)$ \\
Right & $4(28.6 \%)$ \\
Left & \\
\hline Spasticity & $2(14.3 \%)$ \\
Grade 1 & $12(75.7 \%)$ \\
Grade 1+ & $5(35.7 \%)$ \\
\hline GMFCS & $9(64.3 \%)$ \\
Level I & \\
Level II & $6.96 \pm 0.987$ \\
\hline Age(Years) & $X^{-} \pm$SD
\end{tabular}

GMFCS: Gross motor functional classification system, $\mathrm{X}^{-} \pm \mathrm{SD}$ : Mean \pm Standard deviation

\section{Pediatric balance scale results}

Table (2) represents the comparisons of pre and post treatment mean values of PBS of the study sample. The mean values of pre- and post-treatment of PBS were $36.14 \pm 6.024$ and $46.71 \pm 4.795$, respectively. The statistical analysis by Student $t$ test revealed that there was a statistical significant improvement $(\mathrm{P}<0.05)$ of $\mathrm{PBS}$ in post-treatment compared to pre-treatment values within the study sample. 
Table (2): Comparison of mean values of pediatric balance scale preand post-treatment within the study sample.

\begin{tabular}{|l|l|}
\hline Items & PBS \\
\hline Pre-treatment & $\mathbf{3 6 . 1 4} \pm 6.024$ \\
\hline Post-treatment & $\mathbf{4 6 . 7 1 \pm 4 . 7 9 5}$ \\
\hline T-value & $-\mathbf{1 5 . 0 8 1}$ \\
\hline P-value & $\mathbf{0 . 0 0 0}$ \\
\hline Significance & S \\
\hline
\end{tabular}

Data are expressed as mean and standard deviation (SD) P-value: probability S: significant

\section{DISCUSSION}

The aim of this study was to investigate the effect of task oriented training on balance in children with hemiparetic cerebral palsy.

Cerebral palsy may affect the child on several health dimensions; the motor signs include primary neuromuscular deficits, such as spasticity, muscle weakness, imbalance and decreased selective motor control and secondary musculoskeletal problems such as bony malformations and

contractures (Siri et al., 2010).

Choosing the age of the children was in agreement with Eccles (1999) who reported that child has a good balance like adult between age of 5 and 10 years.

It was intended to assess the balance for children with HCP which comes in accordance with Flodmark (2003) who found that HCP child has difficulty in balance and walking which is manifested by a shorter step length and more stiffness of the affected side when compared with normal child of the same age. Also, Torres and Ting (2007) who reported that the ability of the human to maintain normal balance depends on activity of group of muscles that balance the spinal column while there is a difficulty in HCP children to overcome the spasticity.

Significant improvement of balance in this study is supported by the findings of Kyung and Yijung (2016) who examined the effects of Task-oriented training for gait and balance in

cerebral palsy. Twelve patients were experimental group who executed the task-oriented training (5 times/wk.) for 4 weeks. They found significant increase of balance and gross motor function.

Moreover, the results of this study agree with findings of Franklin (2016) who explore the effectiveness of task oriented training on mobility and balance among spastic diplegic cerebral palsy children. Twenty spastic diplegic CP fulfilled inclusion and exclusion criteria were 
selected for the study and randomly divided into two groups A and B. Group A received task oriented training and group B received conventional physiotherapy for a period of six weeks.

Before starting the treatment, mobility and balance were measured by timed up and go test and pediatric balance scale respectively. The measurements were repeated after six weeks. The results showed that both task oriented training and conventional physiotherapy were effective in improving mobility and balance among spastic diplegic children, but when comparing both task oriented training group showed more improvement in mobility and balance among spastic diplegic children than conventional physiotherapy group.

The current study has some limitations such as the small sample that it may not be possible to generalize these results to the whole population of children with hemiplegic $\mathrm{CP}$. Further studies on a larger population of children with hemiplegic $\mathrm{CP}$ have to be carried out. Additionally, the children who participated in this study were restricted to one type of $\mathrm{CP}$ with the age group from six to nine years. So, more studies are needed on other types of CP.

\section{CONCLUSION}

Based on the results of this study, task oriented training program may be a beneficial method in the rehabilitation of children with hemiplegic $\mathrm{CP}$ to improve balance.

\section{ACKNOWLEDGMENTS}

The authors thank all the children and parents who participated in this study.

\section{REFERENCES}

Bayona, N. ; J. Bitensky ; K. Salter, et al. (2005): The role of taskspecific training in rehabilitation therapies. Top Stroke Rehabilitation.; 12: 58-65.

Ching, Y. ; H. Pai-Chuan ; C. Yu-Ting ; L. Keh-Chung and Y. Hsin Wen (2013): Effects of Mirror Therapy on Motor and Sensory Recovery. A Randomized Controlled Trail. Physical, Medical and Rehabilitation, 76 (8): 406-12.

Citation, N. and H. Ostwal (2016): Impact of task-oriented training on balance in spastic cerebral palsied children. Physiotherapy Quarterly, 28(2): 52-56.

Eccles, J. (1999): The development of children ages 6 to 14. The Future of Children., 9(2): 30-44. 
Feltham, M. ; A. Ledebt ; F. Deconinck and G. Savelsbergh (2010): Assessment of neuromuscular activation of the upper limbs in children with spastic hemiparetic cerebral palsy during a dynamical task. J Electromyogr Kinesiol.; 20 (3): 448-456.

Flodmark, O. (2003 ): Brain imaging studies of individuals with cerebral palsy. Rivista di Neuroradiologia.; 16(2):183-184

Franjoine, M. ; N. Darr ; S. Held ; K. Kott and B. Young (2010): The performance of children developing typically on the pediatric balance scale. Pediatric Physical Therapy, 22(4): 350-359.

Franjoine, M. ; J. Gunther and M. Taylor (2003): Pediatric Balance Scale: a modified version of the Berg Balance Scale for the school-age child with mild to moderate motor impairment. Pediatric Physical Therapy.;15: 114-128.

Franklin, S. (2016) : Efficacy of Task Oriented Training on Mobility and Balance among Spastic Diplegic Cerebral Palsy Children. RVS College of Physiotherapy Journal, India Submission., 27:9-17.

Jauregui-Renaud, K. (2013): Postural Balance and Peripheral Neuropathy, Nizar Souayah, Intech Open, DOI: 10.5772/55344.

Ki, K. ; S Mi ; M. Young and D. Jong (2015): "Effects of auditory feedback during gait training on hemiplegic patients' weight bearing and dynamic balance ability." Journal of Physical Therapy Science.; 27(4): 1267-1269.

Kyung, H. and C. Yijung (2016): Effects of task-oriented training for Gross Motor Function Measure, balance and gait function in children with cerebral palsy. Physical Therapy Rehabilitation Science, 5 (1): 9-14.

Lei, Y. ; C. Lam ; M. Lam et al., (2017): Validity and Reliability of Timed Up and Go Test on Dynamic Balance in 3-5 Years Old Preschool Children. Journal of Yoga and Physical Therapy, 7 (2): 266.

Leroux, A. ; H. Pinet and S. Nadeau (2008): Task-oriented intervention in chronic stroke: changes in clinical and laboratory measures of balance and mobility. Neurorehabilitation and Neural Repair, 22(6): 649-660.

Odding, E. ; M.E. Roebroeck and H.J. Stam (2006): The epidemiology of cerebral palsy: incidence, impairments and risk factors. Disability Rehabilitation.; 28(4):183-191. 
Rosenbaum, P. ; N. Paneth ; A. Leviton et al., (2007): A report: the definition and classification of cerebral palsy. Developmental Medical Child Neurological Supply. 109 (suppl 109): 8-14.

Siri, M. ; G. Ann and V. Beatrix (2010): Relationship between body functions and upper extremity activity in children with cerebral palsy. Developmental Medicine \& Child Neurology, 52: 29-34.

Torres-Oviedo, G. and L. Ting (2007): Muscle synergies characterizing human postural responses. Journal of Neurophysiology.; 98(4): 2144-2156.

$$
\begin{aligned}
& \text { تأثير التدريب الموجه على الاتزان لاى الأطفال المصابين بالفالج الشقى }
\end{aligned}
$$

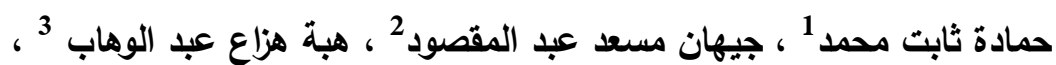

$$
\begin{aligned}
& \text { عمرو عبد الله عزام } 4 \\
& \text { 1- اخصائى علاج طبيعى بالمعهد القومي للجهاز العصبى الحركى مصر . } \\
& 2 \text { - أستاذ بقسم العلاج الطبيعي للأطفال - كلية العلاج الطبيعي - جامعة القاهرة. } \\
& \text { 3- مدرس بقسم العلاج الطبيعي للأطفال - كلية العلاج الطبيعي - جامعة القاهرة. } \\
& \text { 4- استاذ جراحة العظام ،المعهد القومى للجهاز العصبي الحركى. }
\end{aligned}
$$

الخلفية: يعتبر التدريب الموجه وسيلة فعالة لتحسين التوازن. الغرض العهام : الهدف من هذه الدراسة

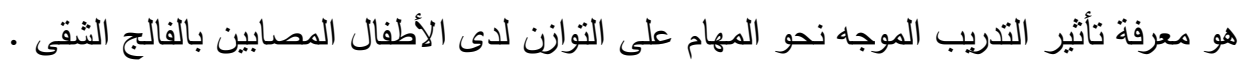

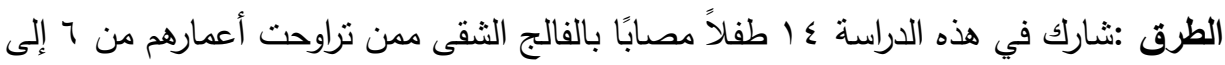

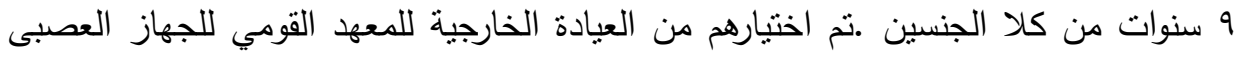
الحركى .احتوت هذه الدراسة على مجموعة واحدة .تلقت مجموعة الدراسة برنامج التدريب

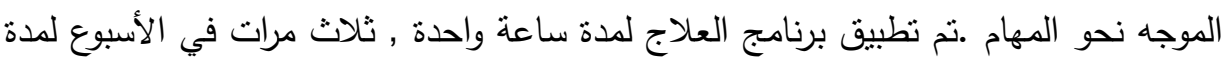

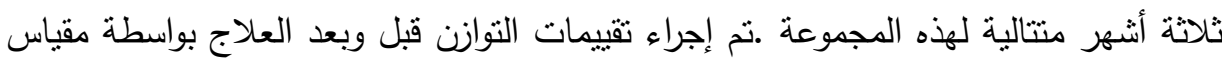
توازن الأطفال .النتائج : أظهرت النتائج تحسن ذو دلالة احصائية فى التوازن بعد انتهاء مدة العلاج.

الاستنتاجات : يمكن استخدام التدريب الموجه نحو المهام ضمن برنامج التأهيل كوسيلة فعالة

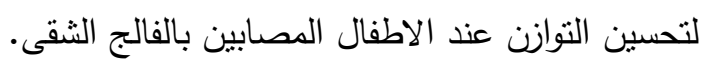
الكلمات المفتاحية :الثلل الدماغي , الثلل النصفى , الندريب الموجه نحو المهام , التوازن ,

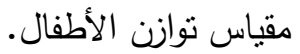

